\title{
FORMAÇÃO DO PROFESSOR DE ENSINO RELIGIOSO: ESTUDO DAS GRADES CURRICULARES NOS CURSOS DE PEDAGOGIA PRESENCIAL DA CIDADE DE CASCAVEL-PR
}

\author{
Education of Religious Education teachers: \\ a study of the curriculum of Pedagogy \\ in-classroom courses in Cascavel (Paraná)
}

\author{
Kellys Regina Rodio Saucedo* \\ Vilmar Malacarne**
}

\begin{abstract}
RESUMO
No Estado do Paraná, a Deliberação n ${ }^{\circ}$ 01/06 do Conselho Estadual de Educação prioriza o exercício da docência do Ensino Religioso nos anos iniciais do Ensino Fundamental para os pedagogos e nos anos finais, entre outras licenciaturas, exige-se especialização em Ensino Religioso. Com o objetivo de investigar a formação do pedagogo para atuar com essa disciplina, realizou-se um levantamento de documentos, leis federais, estaduais e um estudo da grade curricular de quatro Instituições de Ensino Superior (IES) que ofertam a graduação em Pedagogia presencial, na cidade de Cascavel, Paraná. Os resultados desses dados indicaram a ausência de conteúdos que relacionem conhecimentos de ênfase científica a conhecimentos sobre cultura religiosa nas quatro instituições investigadas. Conclui-se que, não obstante a existência de leis que assegurem a disciplina de Ensino Religioso nas escolas de Ensino Fundamental, é emergente a necessidade de políticas efetivas que promovam a profissionalização dos pedagogos para esta área do conhecimento, inserindo nas grades curriculares dos cursos de formação inicial conteúdos ou disciplina com os fundamentos para a docência do Ensino Religioso.
\end{abstract}

Palavras-chave: Ensino Religioso; formação de professores; Pedagogia.

* Bolsista CAPES/DS. Aluna do Programa de Pós-Graduação Stricto Sensu em Educação/ CECA/UNIOESTE. gildone@hotmail.it

** Doutor em Educação. Docente do Programa de Pós-Graduação Stricto Sensu em Educação CECA/UNIOESTE. vilmar.malacarne@unioeste.br 


\begin{abstract}
In the state of Paraná (Brazil), the Deliberation 01/06 of the State Board of Education assigns the teaching of Religious Education in the early years of Elementary School to educators (pedagogues), and, for the final years, among other degrees, the Law requires specialization in Religious Education. In order to investigate the pedagogue's education for working with this subject, we examined documents, federal and state laws, and the curriculum of four Higher Education Institutions that offer undergraduate education in Pedagogy (in-classroom format), in Cascavel, Paraná. The results of the data analysis indicated a lack of contents that relate the predominantly scientific knowledge with knowledge on religious culture in the four institutions investigated. We conclude that, despite the existence of laws that ensure the offer of Religious Education in the Elementary School, there is an emerging need for effective policies that promote the professionalization of educators for this area of knowledge, by including contents or a subject with the foundations for the teaching of Religious Education in the curriculum of initial education courses.
\end{abstract}

Keywords: Religious Education; teacher education; Pedagogy.

\title{
Introdução
}

A escola é o espaço em que ocorrem, ou deveriam ocorrer, as reflexões sobre o conhecimento produzido historicamente pelo homem. No seu interior, transitam conhecimentos científicos e a cultura popular, muito embora essa relação entre ciência e cultura nem sempre se configure de maneira pacífica. Os embates entre Ciência e cultura popular têm raízes históricas e estão pautados na hierarquização dos saberes. Os currículos escolares na atualidade, via de regra, seguem uma classificação, validando o conhecimento produzido a partir do seu valor enquanto produção científica. O próprio conhecimento escolar também é julgado pelo viés da Ciência e, muitas vezes, é entendido como uma distorção deste conhecimento (LOPES, 2000).

Os estudos recentes pautados em Vygotsky afirmam a existência de conceitos cotidianos e conceitos científicos (DUARTE, 2000), sendo que, para esse autor, os primeiros são superados pela incorporação do conheci- 
mento científico. Essa concepção se opõe à noção de existência de diferentes saberes (FREIRE, 1996), desfavorecendo o diálogo entre os mesmos. Nesse caso, "[...] todo desacordo, teórico ou não, poderia e deveria resultar em um convite à reflexão responsável sobre em que mundo se deseja viver com o outro, ou seja, em mais e mais conversar" (MATURANA, 1997, p. 22).

$\mathrm{Na}$ formação inicial de professores, os dois posicionamentos teóricos mencionados acima estão em constante movimento e integram a constituição profissional dos egressos de cursos de licenciatura. Na teoria e na prática, a definição por um deles fará parte dos princípios adotados em sala de aula para propiciar o ensino e a aprendizagem dos seus futuros alunos. Nesse caso, a formação de professores envolve o princípio da simetria invertida, ou seja, que este seja preparado em condições semelhantes àquela em que irá atuar (OLIVEIRA, 2009). Apesar de este princípio procurar minimizar os conflitos entre formação inicial e atuação, na prática não é o que ocorre. Em geral, os graduados encontram dificuldades para exercer a profissão ao se depararem com condições adversas à sua formação.

Entre os novos rumos da educação e do ofício do professor indicados pela LDB no 9.394/96, no artigo 33 está a incorporação do Ensino Religioso no conjunto de conteúdos mínimos do Ensino Fundamental. Diante deste fato, o objetivo do presente artigo está em analisar as legislações federal e estadual sobre essa área do conhecimento e compreender as implicações que estas regulamentações geraram para a formação do professor de Ensino Religioso. A priori uma questão se destaca: quais cursos de graduação seriam os responsáveis pela formação do professor de Ensino Religioso para o Ensino Fundamental?

Quanto a esse questionamento, partiu-se da Deliberação $n^{\circ}$ 01/06 do Conselho Estadual de Educação do Paraná, que delega aos Pedagogos a prioridade para docência do Ensino Religioso nos anos iniciais do Ensino Fundamental. O foco da pesquisa, portanto, será a formação do Pedagogo para os anos iniciais do Ensino Fundamental, uma vez que, para o atendimento dos anos finais, o mesmo documento exige deste profissional, além da graduação, a especialização em Ensino Religioso.

Diante da definição de quem é o professor responsável pela disciplina no Estado do Paraná, novas questões surgiram, a saber: em quais princípios se pautou o relator da deliberação para definir tal critério para a docência nos anos iniciais? Seria na compreensão de que a formação geral do Pedagogo 
tem na base de seu currículo conhecimentos científicos e de diversidade cultural, como propõem as Diretrizes Curriculares Nacionais para o Curso de Graduação em Pedagogia, licenciatura? Poderia ser, ainda, simplesmente pelo fato de este ser o responsável por este período escolar? Por uma ou outra forma, estão estes Pedagogos sendo formados para mais esta função?

$\mathrm{Na}$ intenção de verificar tal orientação, foram escolhidas quatro Instituições de Ensino Superior (IES), em Cascavel-Paraná, que ofertam o Curso de Pedagogia presencial, para análise e estudo de suas grades curriculares.

A opção pela pesquisa qualitativa (GRESSLER, 2004) se deu por sua característica interpretativa e pela possibilidade de ampliar a investigação sobre a formação dos Pedagogos. Para tal empreendimento, a análise de dados partiu da pesquisa documental, buscando compreender a organização do Ensino Religioso na atual legislação brasileira. A pesquisa bibliográfica teve por foco compreender a mudança de paradigma desta disciplina pós-LDB n ${ }^{\circ}$ 9.394/96, para, somente então, nas grades curriculares dos cursos de Pedagogia, identificar como aparecem e se são contemplados conteúdos ou disciplinas relacionados à dimensão religiosa que preparariam os futuros professores para o trabalho em sala de aula com o Ensino Religioso.

\section{A legislação do Ensino Religioso: desdobramentos na formação de professores}

Nas últimas décadas, a educação tem sido campo de várias transformações. Em muitos países, a educação assumiu a prioridade nos debates sociais e governamentais, sendo vista como uma entre as mais significativas problemáticas para o desenvolvimento e o futuro das nações. As licenciaturas em Pedagogia, por sua vez, abarcaram em seus currículos a diversificação dos conteúdos, envolvendo diversos conhecimentos, como: histórico, filosófico, antropológico, ambiental, psicológico, linguístico, sociológico, político, econômico e cultural.

Nesse contexto educacional de transformações está o Ensino Religioso com uma nova proposta epistemológica, voltada para o respeito à diversidade cultural religiosa dos povos. A princípio, a Lei de Diretrizes e 
Bases da Educação Nacional - LDB n 9.394/96, no artigo 33 (respaldada no artigo 210 da Constituição Federal de 1988), permitia ao aluno ou ao seu responsável optar pelo ensino confessional ou interconfessional da disciplina. Com a publicação da Lei $n^{0} 9.475 / 97$, a redação do artigo 33 da LDB foi alterada e o Ensino Religioso, vedado de formas proselitistas, passou a configurar como elemento básico da formação integral do aluno. A oferta da disciplina é, portanto, obrigatória nos horários normais das escolas públicas, mas a matrícula do aluno é facultativa ${ }^{1}$ (GARUTTI, 2006; DERISSO, 2009; JUNQUEIRA, 2012).

Dois pontos mudaram o paradigma do Ensino Religioso, por meio da Lei $\mathrm{n}^{\circ}$ 9.475/97, conforme Garutti (2006). O primeiro ponto se refere ao eixo de ensino que passou a ser o estudo do fenômeno religioso (JUNQUEIRA, 2001). Tanto a pluralidade de manifestações culturais religiosas quanto a inexistência de um credo devem ser respeitadas, tendo como foco pedagógico " [...] o fenômeno religioso presente na sociedade, com a abertura do homem no sentido fundamental de sua existência, seja qual for o modo como seja percebido este sentido" (JUNQUEIRA, 2001, p. 10). Essa orientação responde à necessidade de uma escola em que os princípios plurais e laicos sejam considerados por seus conviveres, em que as pessoas saibam dialogar entre si, pautadas em princípios de alteridade ${ }^{2}$. A ideia de diálogo se insere no novo paradigma de ensino, superando o conceito de tolerância e respeito, conforme o Parecer $n^{\circ}$ 4/98 do Conselho Nacional de Educação/CEB:

[...] as escolas deverão reconhecer que as aprendizagens são constituídas pela interação entre os processos de conhecimento com os de linguagem e os afetivos, em consequência das relações entre as distintas identidades dos vários participantes do contexto escolarizado; as diversas experiências de vida de alunos, professores e demais participantes do ambiente escolar, expressas através de múltiplas formas de diálogo [...] [grifo dos autores] (BRASIL, 1998, p. 13).

1 A Lei n 9475/97 também removeu a expressão "sem ônus para os cofres públicos", que desobrigava o Estado da responsabilidade pela contratação de professores. Essa ação pressupõe o tratamento pedagógico da disciplina, invalidando as práticas confessionais.

2 Cf. Oliveira (2003), a alteridade pressupõe relações de diálogo com o outro, exercitando a escuta, a procura de conhecer o outro em diferentes espaços e situações. Dialogar vai muito além de falar do outro ou para o outro, consiste em conjugar a alteridade no direito à diferença. 
Percebe-se, no conjunto de orientações para o desenvolvimento do processo de aprendizagem, a instrução para o diálogo e o estabelecimento de relações entre os saberes culturais e científicos, envolvendo valores de vida na identidade pessoal daqueles que participam do ambiente escolar. Com essa nova formatação, o Ensino Religioso, no contexto educacional contemporâneo, passa a ser entendido como:

[...] um dos lugares e espaços em que se destacam e discutem posições sobre o sentido da vida, do ser humano, na perspectiva da liberdade do ensino, como forma de construção da liberdade humana. Esta é, seguramente, uma das maiores dificuldades que a humanidade enfrenta: permitir ao outro ser sujeito de sua cultura e de seus desejos, de modo especial quando os desejos dele interferem na vontade e nos interesses de outrem (OLIVEIRA et al., 2007, p. 36).

O pressuposto para o diálogo, portanto, não significa necessariamente que um conhecimento prevalecerá sobre o outro, mas que eles se deram, a saber, a conhecer e a compreender sua existência. Diálogo este que não acontecia na sala de aula e, em alguns casos, permanece inalterado, mesmo após a LDB em vigor. Para a efetivação e o início do diálogo foi preciso reformular seus princípios e nesta reformulação está a importância do segundo ponto. Este diz respeito à remoção do aspecto confessional até então presente na legislação nacional. Condição de alteração seguramente dada pela ampliação dos direitos e da liberdade dos sujeitos o que

[...] permitiu que condutas religiosas, sexuais, étnicas e culturais aflorassem de forma ampla, colocando-nos de frente com os mais diversos comportamentos. Pensar um currículo capaz de respeitar e valorizar a gama de manifestações presentes na sociedade é uma das condições para que a liberdade e o desenvolvimento individual estejam no centro da formação escolar. $\mathrm{O}$ direito à diferença se coloca aqui como a base para constituição de uma identidade cultural, tanto individual quanto nacional (MALACARNE, 2011, p. 51).

Entende-se, com isso, que a LDB n ${ }^{\circ}$ 9.394/96, ao vedar manifestações proselitistas (BRASIL, Lei ${ }^{\circ}$ 9.475/97) nas aulas de Ensino Religioso, 
respondeu aos anseios da sociedade contemporânea e exigiu um novo rumo para os estudos escolares dessa disciplina. Com o objetivo específico de impedir o ensino doutrinário, vigente desde as primeiras formas de estudo da religião na educação brasileira, o Ensino Religioso assumiu formalmente o respeito à diversidade cultural religiosa do Brasil. Nas palavras de Costella (2004), pode-se dizer que:

[...] aquilo que para as igrejas é objeto de fé, para a escola é objeto de estudo. Isto supõe a distinção entre fé/crença e religião, entre o ato subjetivo de crer e o fato objetivo que o expressa. Essa condição implica a superação da identificação entre religião e igreja, salientando sua função social e o seu potencial de humanização das culturas [...] A instituição escolar deve reivindicar a título pleno a competência sobre essa matéria (p. 105-106).

Para se chegar, portanto, à escolarização do Ensino Religioso laico e plural, fez-se necessária a construção de parâmetros específicos para superação de obstáculos político-pedagógicos e epistemológicos presentes na disciplina. A tarefa de elaborar um documento nacional para a atual legislação ficou sob a responsabilidade do Fórum Nacional Permanente do Ensino Religioso (FONAPER). O documento, intitulado Parâmetros Curriculares Nacionais do Ensino Religioso (PCNER), foi divulgado em 1997, um ano após a elaboração dos Parâmetros Curriculares Nacionais (PCN's) pelo Ministério da Educação e da Cultura (MEC).

Tanto a promulgação da Lei $\mathrm{n}^{\circ} 9.475 / 97$ quanto a publicação dos PCNER provocaram a ruptura de décadas de um modelo de ensino catequético. Para Toledo e Amaral (2004, p. 3), o Ensino Religioso “[...] nunca antes possuiu o caráter que lhe é impresso: criou-se uma identidade pedagógica para o Ensino Religioso que tem como pressuposto fundamental a formação básica do cidadão". Diante desses parâmetros e da normatização em vigor, os sistemas de ensino passaram a (re)organizar o currículo do Ensino Religioso em todo país. Coube, portanto, aos sistemas de ensino estaduais os procedimentos para definir os conteúdos do Ensino religioso e o estabelecimento de orientações para habilitação e admissão de professores (BRASIL, Lei n ${ }^{\circ}$ 9.475/97). 


\section{Professores de Ensino Religioso: quem eram e quem são?}

No Estado do Paraná, o Ensino Religioso por um longo período ficou sob a responsabilidade de "[...] professores voluntários ligados a denominações religiosas e, consequentemente, sofriam forte influência do caráter confessional dessas instituições" (PARANÁ, 2008, p. 40).

A LDB n ${ }^{\circ} 4.024 / 61$ manteve a dispensação de custas para o Estado, no artigo 97, ao afirmar que o provimento destes professores não deveria gerar ônus para os cofres públicos. A promulgação da LDB n 9.394/96, no artigo 33, levou a uma série de discussões em âmbito nacional. A expressão "sem ônus para os cofres públicos" suscitou a necessidade de responsabilização do Estado em relação à contratação e à habilitação de professores, ou seja, o tratamento isonômico em relação às demais disciplinas. Três proposições de alterações foram sugeridas: (i) exclusão do texto "sem ônus para os cofres públicos", justificada por sua integração entre as dez áreas de conhecimento e, portanto, dever constitucional do Estado na formação do cidadão; (ii) remoção de formas doutrinárias de ensino (confessional e interconfessional); (iii) solicitação da laicidade para o Ensino Religioso, garantia de respeito às diversas culturas. As três propostas foram sintetizadas pelo deputado Padre Roque Zimmermann e o projeto substitutivo foi aprovado em junho de 1997, quase por unanimidade (JUNQUEIRA, 2012). O documento final foi aprovado no Senado da República sem emendas e resultou na atual organização do Ensino Religioso, conforme a Lei ${ }^{\circ}$ 9.475/97, que alterou a redação do artigo 33 da LDB nº 9.394/96:

Art. 33. O ensino religioso, de matrícula facultativa, é parte integrante da formação básica do cidadão e constitui disciplina dos horários normais das escolas públicas de ensino fundamental, assegurado o respeito à diversidade cultural religiosa do Brasil, vedadas quaisquer formas de proselitismo.

$\S 1^{\circ}$. Os sistemas de ensino regulamentarão os procedimentos para a definição dos conteúdos do ensino religioso e estabelecerão as normas para a habilitação e admissão dos professores.

A atribuição para habilitação e admissão de professores, finalmente, passou a ser da competência do Estado e não mais uma tarefa de voluntários. Essa condição demandou a preparação específica, pois conforme “[...] 
a nova proposta para o Ensino Religioso, os requisitos exigidos para esse profissional não estão fundamentados na atitude religiosa, mas no conhecimento do fenômeno religioso em todas as suas dimensões" (MALVEZZI; TOLEDO, 2010, p. 191).

Em agosto de 2002 o Conselho Estadual de Educação do Paraná (CEE) aprovou as Deliberações n ${ }^{\circ}$ 03/02 e n ${ }^{\circ}$ 07/02, regulamentando o Ensino Religioso nas Escolas Públicas do Sistema Estadual de Ensino do Paraná. Entre os pressupostos a que se subordinam os conteúdos e a postura didático-pedagógica, destacados pela Deliberação $n^{\circ} 03 / 02$, no $\operatorname{artigo~} 2^{\circ}$, estão:

a) da concepção interdisciplinar do conhecimento, sendo a interdisciplinaridade um dos princípios de estruturação curricular e da avaliação;

b) da necessária contextualização do conhecimento, que leve em consideração a relação essencial entre informação e realidade; c) da convivência solidária, do respeito às diferenças e do compromisso moral e ético;

d) do reconhecimento de que o fenômeno religioso é um dado da cultura e da identidade de um grupo social, cujo conhecimento deve promover o sentido da tolerância e do convívio respeitoso com o diferente;

e) de que o ensino religioso deve ser enfocado como área do conhecimento em articulação com os demais aspectos da cidadania.

Estes pressupostos estavam articulados a elementos mais amplos, como a Constituição de 1988, a Lei de Diretrizes e Bases da Educação - Lei $\mathrm{n}^{\circ}$ 9.394/96, as Diretrizes Curriculares do Ensino Fundamental e a Resolução $\mathrm{CNE} / \mathrm{CEB} n^{\circ} 2 / 98$. A sua aprovação por meio da Deliberação $n^{\circ}$ 03/02 levou à elaboração da Instrução Conjunta $n^{\circ}$ 001/02 do Departamento do Ensino Fundamental (DEF)/Secretaria do Estado do Paraná, desencadeando alterações na proposta de ensino e na formação de professores.

A Instrução ${ }^{0}$ 001/02 DEF/SEED estabeleceu para as séries iniciais do Ensino Fundamental o ensino da disciplina pelo professor da turma e para os anos finais especialistas em Pedagogia do Ensino Religioso ${ }^{3}$ ou licenciados em Filosofia, História, Ciências Sociais ou Pedagogia.

3 No ano de 1987, a Secretaria de Estado da Educação do Paraná, em parceria com a Associação Interconfessional de Curitiba (Assintec) e PUC/PR, iniciou o curso de Especialização em Pedagogia Religiosa com a intenção de formar professores em bases que valorassem a pluralidade religiosa no ensino. 
Os impasses sobre a contratação de professores, apesar da Instrução $\mathrm{n}^{\circ}$ 001/02 DEF/SEED, estavam longe de serem resolvidos (Parecer $\mathrm{n}^{\circ} 464 / 03$ CEE; Instrução Conjunta n ${ }^{\circ}$ 005/04 SEED/SUED/DEF), fato que levou ao Sistema Estadual de Ensino do Paraná o encaminhamento de questões para o Conselho Estadual de Educação (CEE) referentes ao tratamento curricular da disciplina e proposições, entre elas, a alteração nos requisitos para docência do Ensino Religioso. Diante das solicitações, a Câmara de Legislação e Normas do CEE aprovou o Parecer $n^{\circ} 01 / 06$, sendo, posteriormente, "[...] aprovada pelo Conselho Estadual de Educação (CEE) a Deliberação ${ }^{\circ}$ 01/06, que revogou, no art. $9^{\circ}$, as deliberações anteriores e as disposições em contrário" (MALVEZZI; TOLEDO, 2010, p. 194).

Desde então, para o exercício da docência no Ensino Religioso no Estado do Paraná, exige-se, em ordem de prioridade, para os anos iniciais, a graduação em Curso de Pedagogia, e para os anos finais, a formação em cursos de licenciatura na área das Ciências Humanas, preferencialmente em Filosofia, História, Ciências Sociais e Pedagogia, com especialização em Ensino Religioso.

Delegou-se às mantenedoras de ensino a responsabilidade pelo desenvolvimento de programas de formação docente em conformidade com a Deliberação $n^{\circ} 01 / 06 \mathrm{CEE}$, pensando em uma formação que responda às exigências do novo paradigma educacional dado ao Ensino Religioso no que se refere à composição do quadro de professores, dos encaminhamentos metodológicos, da avaliação e da formação continuada de professores.

Pensar na habilitação e na admissão dos professores significa pensar na formação inicial destes, portanto, na licenciatura plena, nos conteúdos e nas disciplinas que integram as grades curriculares das Instituições de Ensino Superior. Não foram investigadas nesta pesquisa, como já apontado anteriormente, todas as licenciaturas indicadas na atual legislação. Optou-se como objeto de estudo pelas grades curriculares dos cursos de Pedagogia presencial, haja vista que para os anos iniciais não é exigida a especialização em Ensino Religioso, diferente do que acontece nos anos finais, em que a especialização nesta área se constitui um dos critérios de distribuição de aulas. 


\section{Métodos e resultados}

A amostra da pesquisa é composta pelas grades curriculares de cursos de Pedagogia Presencial ofertados em quatro Instituições de Ensino Superior, sendo uma instituição estadual e três particulares, localizadas em Cascavel, no Oeste do Paraná. Estas receberam a seguinte identificação: IES1, IES2, IES3 e IES4, conforme a ordem de alteração da última grade curricular de cada curso.

O contato com as Instituições de Ensino Superior aconteceu por meio de Carta de Apresentação, explicando a intenção da pesquisa. A grade curricular dos cursos de Pedagogia foi fornecida pelos coordenadores de ensino desses cursos, de maneira direta ou pela internet, conforme conveniência da instituição. A análise das grades partiu do pressuposto de que estas trazem elementos para compreensão da base formativa inicial dos professores de Pedagogia para atuação com a disciplina de Ensino Religioso nos anos iniciais do Ensino Fundamental. Em todos os casos, a investigação transcorreu baseada na grade curricular que está em vigor e para cada uma das quatro instituições apresentar-se-á uma breve caracterização do curso, seguida de análise sucinta da composição curricular.

O perfil profissional na IES1 integra a formação geral e específica, podendo o pedagogo atuar no ensino, na organização e na gestão de sistemas. A última reestruturação do curso aconteceu em 2007 e passou a vigorar em 2008, por exigência legal em resposta às adequações presentes nas Diretrizes Curriculares Nacionais para o Curso de Graduação em Pedagogia (Resolução $\mathrm{CNE} / \mathrm{CP} \mathrm{n}^{\circ} 1 / 2006$ ) e para atender a obrigatoriedade de inclusão de Libras como disciplina curricular (Decreto $n^{\circ} 5.626 / 2005$ ). Conforme os documentos legais da própria instituição, não ocorreram alterações substanciais na grade curricular, mas simplesmente uma adequação às exigências já mencionadas. Apesar de mencionar a Resolução do CNE/ $\mathrm{CP}^{\circ}$ 01/2006 no bloco de disciplinas denominado formação diferenciada, composto por Teorias, Práticas de Ensino e conteúdos específicos dos anos iniciais do Ensino Fundamental, não existe nada sobre a área de Ensino Religioso na grade curricular desta IES.

No caso da IES2, a última alteração na grade curricular do curso de Pedagogia ocorreu em 2011. O egresso do curso recebe a habilitação em Pedagogia, na modalidade licenciatura, podendo atuar, também, na gestão 
escolar e em funções de Organização do Trabalho Pedagógico em ambientes escolares e não escolares. Na grade curricular do curso existe uma disciplina cuja base é o multiculturalismo. Em conversa com o coordenador do curso, questionou-se sobre conteúdos de religião, se estes faziam parte da ementa da disciplina. A resposta foi negativa, portanto, os alunos deste curso não têm contato com qualquer conteúdo que possa promover uma formação para o exercício do diálogo relacionado às diversas culturas religiosas ou liberdade de escolha por uma postura ateísta, cética ou agnóstica dos alunos.

Semelhante posição revela a grade curricular, aprovada em 2011, da IES3 ao apresentar disciplinas que indicam conteúdos sobre as novas tecnologias, antropologia cultural, artes, políticas de inclusão, entre outras áreas, atendendo a Resolução do $\mathrm{CNE} / \mathrm{CP}^{\circ}{ }^{\circ}$ 01/2006. Entretanto, ao questionar-se o coordenador sobre a presença de conteúdos sobre diversidade cultural religiosa nas ementas dos planos de ensino, este negou sua existência. Este profissional recebe a habilitação para atuar nas áreas da docência na Educação Infantil, nos anos iniciais do Ensino Fundamental, no Ensino Médio na modalidade normal de Educação Profissional, além de áreas de apoio escolar e gestão de sistemas escolares e não escolares e implantação de projetos em sistemas formais e não formais de educação.

A última grade analisada desta lista se refere à IES4. A instituição habilita os pedagogos para atuação em espaços escolares e não escolares, tanto para práticas pedagógicas quanto para gestão educacional, titulação idêntica ao modelo da IES2. A instituição reformulou sua matriz curricular em 2012, mas sua implantação teve início apenas em 2013. A nova proposta inclui uma disciplina com conteúdos sobre educação e diversidade, sendo a carga horária de 100 horas, distribuída em 60 horas teóricas; 20 horas de prática pedagógica e 20 horas para outras atividades não especificadas na ementa. O cronograma das aulas é organizado por semanas e, entre outros conteúdos, estão presentes: multiculturalismo, direitos humanos, questões raciais, de gênero e bullying; inclui, ainda, na relação de conteúdos um tópico sobre religião e crença religiosa na educação. Como nesse caso apareceu a indicação explícita de conteúdos de religião na formação do pedagogo, foram solicitados o Plano de Ensino da disciplina e a bibliografia básica utilizada para a temática. O resultado da análise do Plano de Ensino evidenciou um único texto, norteado pela temática das religiões afro-brasileiras, sendo que na bibliografia complementar não existe qualquer outra referência às diferentes crenças religiosas da população. 


\section{Análise dos resultados}

A educação no Brasil tem abarcado uma série de problemáticas de estudo para explicar as causas do fracasso escolar. Investigações pontuando a influência da quantidade em relação à qualidade do conteúdo; da formação em especialidades ou da formação generalista para cidadania; das teorias à prática pedagógica, foram e continuam sendo temas de pesquisas educacionais. Entretanto, a partir dos anos de 1990 a maior parte das pesquisas tem se detido sobre a formação de professores e a importância do currículo para atuação deste profissional. De acordo com Malacarne (2011, p. 50), "[...] da influência dos educadores ligados às religiões e dos educadores leigos, as concepções e os modelos de currículo mudaram com os anos", influenciados pelas transformações constantes da sociedade, interferindo direta ou indiretamente na atuação do futuro professor.

As Instituições de Ensino Superior nos cursos de Pedagogia têm assegurada a autonomia para formulação de currículos próprios para formação docente, de acordo com as características do alunado e história institucional, pelas Diretrizes Curriculares Nacionais para o Curso de Graduação em Pedagogia (BRASIL, 2006). Nota-se com isso um passo em direção à construção de um currículo que responda às necessidades formativas dos sujeitos. Como pontuado por Giroux e Simon (1995, p. 99), “[...] precisamos de uma pedagogia cujos padrões e objetivos a serem alcançados sejam determinados em conformidade com metas de visão crítica e de ampliação das capacidades humanas e possibilidades sociais". Por outro lado, Libâneo (2006) apresenta uma crítica ácida em relação à Resolução do $\mathrm{CNE} / \mathrm{CP}^{\circ}$ 01/2006 ao declarar "imprecisões conceituais e ambiguidades" presentes no documento, gerando consequências graves para a formação de professores, entre elas: "a) sobrecarga disciplinar no currículo para cobrir todas as tarefas previstas para o professor; b) ausência de conteúdos específicos das disciplinas do currículo do ensino fundamental" (p. 860). Isso significa que, desfeita qualquer ingenuidade primeira, a constituição de um currículo envolve disputas políticas e interesses, por isso, nem sempre são ofertados nos cursos de licenciatura em Pedagogia conteúdos substantivos que atendam todas as áreas do conhecimento que compõem a Base Nacional Comum das escolas de Ensino Fundamental, "[...] levando ao empobrecimento da formação profissional” (LIBÂNEO, 2006, p. 860). Essa carência formativa 
constitui um conjunto de problemáticas para a atuação do professor em sala de aula, em temas que envolvem a necessidade de conhecimentos mínimos para o exercício da docência.

Gatti e Barreto (2009) realizaram um balanço da situação relativa à formação docente no Brasil, em específico sobre o curso de Pedagogia. Nos 71 cursos investigados, os autores concluíram que os conteúdos das disciplinas a serem trabalhados na educação básica são abordados nas grades curriculares de maneira muito genérica ou associados a metodologias e/ou práticas de ensino. Para essa constatação, corroboram os apontamentos de Libâneo (2006),

Em boa parte dos atuais cursos há quase que total ausência no currículo de conteúdos específicos (de português, ciências, matemática, história, etc.), existindo apenas as metodologias. Como formar bons professores sem o domínio desses conhecimentos específicos? Essa exigência se amplia perante as mais atuais concepções pedagógicas, em que o ensino está associado ao desenvolvimento das capacidades cognitivas dos alunos por meio dos conteúdos [...]. Está sendo requerido dos professores que dominem os conteúdos, mas especialmente, o modo de pensar, raciocinar e atuar próprio de cada disciplina [...]. Como fazer isso sem os conteúdos específicos? (p. 861).

Se em disciplinas consideradas de suma importância para as propostas governamentais de educação elementar, como a Língua Portuguesa e a Matemática, os conteúdos permanecem relacionados a metodologias de ensino em doses mínimas, como está a condição de conteúdos que exigem do professor o domínio de conhecimentos sobre as manifestações socioculturais dos povos, como é o caso do Ensino Religioso?

Para Malacarne (2011), um processo formativo fragmentado, que não considere a produção de conhecimentos em seu conjunto ou ignore o papel da religião "[...] na formação do indivíduo e na constituição da sociedade" (p. 238) resulta em dificuldades por parte do professor em abordar temas tanto em aspectos científicos quanto de ordem religiosa. Numa espécie de corrente, e não necessariamente (porque essas questões podem simplesmente serem deixadas de lado), "[...] a dificuldade do professor se transforma em dificuldade para o aprendizado do aluno e, por consequência, em falta de 
clareza para o trato das questões que envolvem estes segmentos no conjunto da vida e na própria produção de conhecimentos" (MALACARNE, 2011, p. 238). A ausência de conteúdos relacionados à religião denuncia a própria dificuldade de constituição de currículos que promovam a formação global destes profissionais, inclusive em relação à inclusão do social e do cultural na esfera científica. Entende-se aqui que as instituições formadoras "[...] necessitam ser reconhecidas como contraesferas públicas. Nossa opinião é que tais instituições, da forma como existem hoje, estão perniciosamente destituídas não só de consciência social, mas também de sensibilidade social" (GIROUX; McLAREN, 1995, p. 127). Um salto na formação acadêmica exige esforços e envolvimento por parte daqueles que organizam os currículos universitários para encontrar variáveis que envolvam ciência e religião com respostas que satisfaçam professores e alunos, considerando suas diferentes concepções científicas e socioculturais.

A formação do pedagogo especificamente detalhada na grade curricular da IES2 inclui temas sobre: diversidade étnico-racial, de gêneros, faixas geracionais, meio ambiente, etc. Essa característica revela a pretensão de atender as condições da Resolução $\mathrm{CNE} / \mathrm{CP} \mathrm{n}^{\circ}$ 01/2006, no artigo $6^{\circ}$, sobre a estrutura do curso de Pedagogia, em específico a alínea "j”, que engloba o "[...] estudo das relações entre educação e trabalho, diversidade cultural, cidadania, sustentabilidade, entre outras problemáticas centrais da sociedade contemporânea". Um empreendimento de difícil execução, como indicam Gatti e Barreto (2009):

Estas postulações criaram tensões para o desenvolvimento curricular desses cursos [...]. Enfeixar todas essas orientações em uma matriz curricular, especialmente para os cursos noturnos, onde se encontra a maioria dos alunos, não é tarefa fácil e está conduzindo a algumas simplificações que podem afetar o perfil dos formandos (p. 50).

Apesar dos esforços, poucos cursos de Pedagogia conseguem oferecer disciplinas que efetivamente atendam as necessidades formativas do professor para Educação Infantil e para os primeiros anos do Ensino Fundamental. No caso indicado acima, a IES2 parece preocupada apenas em responder a uma questão de ordem legislativa do que efetivamente ga- 
rantir melhores condições de ensino-aprendizagem. Visto que, ao incluir na relação dos "conhecimentos relativos à formação profissional específica" uma disciplina de característica multicultural, desconsiderou conteúdos que permitissem aos alunos “[...] compreender o significado das diferentes afirmações de fé e refletir sobre as atitudes morais diferenciadas como consequência do fenômeno religioso que se manifesta na pluralidade cultural religiosa" (OLIVEIRA et al., 2007, p. 116).

Na IES 3, observou-se a inclusão de disciplinas que denotam aproximação com relação às especificações da Resolução do $\mathrm{CNE} / \mathrm{CP} \mathrm{n}^{\circ}$ $01 / 2006$ quanto às situações afloradas no atual contexto social. Se por um lado as orientações são parcialmente atendidas, por outro a ementa dos planos de ensino não apresenta conhecimentos de Ensino Religioso, como relatado pelo coordenador de ensino. Essa condição provavelmente gera dificuldades para os professores que, na escola, precisam estar preparados para formar alunos capazes de "[...] sobreviver nesta sociedade; [e que] para isso precisam da ciência, da cultura, da arte, precisam saber coisas [...] apropriar-se criticamente dos benefícios da ciência e da tecnologia em favor do seu trabalho, da sua vida cotidiana, do seu crescimento pessoal" (LIBÂNEO, 2006, p. 867-868). Por essas evidências, torna-se latente o fato de que os conteúdos específicos do Ensino Religioso, disciplina ministrada nas escolas de Ensino Fundamental, não são matéria dos cursos de formação inicial em Pedagogia, sendo que para essa consideração corroboram os resultados encontrados na IES4, quando da indicação de um único texto sobre uma vertente religiosa. Esse posicionamento desconsidera a pluralidade cultural religiosa existente no Brasil e no mundo.

Nas reformulações, reestruturações ou reorganização das matrizes curriculares destes cursos, todos justificaram a necessidade de atender as disposições presentes na LDB n ${ }^{\circ}$ 9.394/96 e, sobretudo em decorrência da Resolução $n^{\circ} \mathrm{CNE} / \mathrm{CP}^{\circ}$ 01/2006, no quesito da formação plena dos seus alunos para ação educativa que articule conhecimentos científicos, culturais, valores éticos e estéticos, considerando as diferentes visões de mundo. Entretanto, na prática, os currículos continuam insuficientes quanto ao preparo dos futuros professores para o ensino de conteúdos escolares. 


\section{Considerações finais}

A pesquisa permitiu perceber que estamos diante de um problema educacional. Como lidarão os futuros pedagogos em sala de aula, ao enfrentarem situações que exijam conhecimentos sobre religião, não só na disciplina de Ensino Religioso, uma vez que estamos em um espaço geográfico/social em que vigora o forte apelo religioso (MALACARNE, 2011). Apesar de um número expressivo de disciplinas que podem ser classificadas como de formação específica do licenciado, o que sugerem as grades curriculares dos cursos de Pedagogia, pelo menos os analisados por esta pesquisa, é que essa formação ainda acontece de maneira precária quando associada ao conjunto de disciplinas do Ensino Fundamental. Permanecemos diante da dicotomia em que a complexidade entre teoria e prática parece não se realizar a contento, como apontam inúmeros estudos de longa data (ANDRÉ, 2002).

No caso específico do Ensino Religioso, é possível afirmar que a legislação federal principiou as transformações no paradigma desta disciplina no contexto escolar, contudo, não mexeu nos paradigmas solidificados das universidades. Nem a diversidade sociocultural e muito menos questões de religião encontram abertura expressiva para um diálogo efetivo nos currículos dos Cursos de Pedagogia investigados. Esse posicionamento ignora que "[...] o conhecimento produzido nos espaços religiosos entra na escola pública, se não pela porta da frente (através das leis, decretos ou normas curriculares), pela janela, através da religiosidade dos alunos, dos professores, da equipe de direção [...]" (FONSECA, 2006, p. 2), trazendo consigo um arcabouço de dificuldades para aqueles que efetivamente no cotidiano escolar necessitam desses saberes para lidar com a formação plena dos alunos.

Notadamente quase duas décadas se passaram da promulgação da LDB n ${ }^{\circ}$ 9.394/96 e da nova redação do artigo 33 (BRASIL, Lei n ${ }^{\circ}$ 9.475/97) sobre o Ensino Religioso sem avançarmos significativamente no campo formativo de professores. Como consequência disso, são ainda frequentes os momentos em que os docentes desta disciplina assumem uma posição interconfessional cristã, de defesa da sua fé, incluindo vez por outra alguns elementos " [...] sobre outras tradições de matriz oriental, africana e indígena [...] esse profissional por vezes realiza pouca articulação dos conteúdos pro- 
postos com as grandes questões religiosas do ser humano e com a natureza do sagrado", como já haviam constatado os autores Oliveira et al. (2007, p. 58) na década passada. Outro ponto consiste no fato de o professor abordar na maior parte do tempo conteúdos de ênfase científica em sala de aula, o que pode condicioná-lo a ignorar momentos em que seja necessário traçar relações com conhecimentos de religião.

A indicação, ora feita, para essa problemática consiste na inserção de disciplinas cujos conteúdos façam referência ao âmbito específico do Ensino Religioso e não unicamente uma metodologia ou prática de ensino. Muito mais do que o "como ensinar", o professor precisa ter acesso aos fundamentos do Ensino Religioso, com leituras que o auxiliem na compreensão de conceitos básicos do que é hoje sua proposta de ensino, reconhecendo a profundidade e particularidade própria desta área do conhecimento.

Parece, no entanto, que a condição do Ensino Religioso em nosso país não é muito diferente de Libras ou da Educação Especial e que somente se efetivará por meio de decretos nos espaços universitários, uma vez que já existe uma lacuna provocada pela falta de professores habilitados para essa disciplina nos espaços escolares, além da marcada disputa que surge a cada nova proposição e definição da matriz curricular, pois essa traz à tona as problemáticas relacionadas ao status assumido por algumas áreas do conhecimento em relação à distribuição da carga horária que caberá para cada disciplina nos horários semanais. No caso específico do Ensino Religioso, conforme a Instrução Conjunta $n^{\circ}$ 005/04 SEED/SUED/DEF, a carga horária é mínima e corresponde a uma hora/aula semanal.

\section{Referências}

ANDRÉ, M. E. D. A. (Org.). Formação de professores no Brasil (1990-1998). Brasília: MEC/INEP/COMPEd, 2002.

BRASIL. Lei de Diretrizes e Bases da Educação Nacional. Lei $n^{\circ}$. 4024, de 20 de Dezembro de 1961. Disponível em: < http://www.planalto.gov.br/ccivil_03/leis/ 14024.htm>. Acesso em: 25/03/2013. . Constituição da República Federativa do Brasil. Brasília, DF: Senado 
Federal, 1988. Disponível em: <http://www.planalto.gov.br/ccivil_03/Constituicao/ Constituicao.htm>. Acesso em: 27/03/2013.

. Ministério da Educação. Lei de Diretrizes e Bases da Educação Nacional (LDB). Lei no 9.394/96. Brasília, DF: MEC, 20 dez 1996. Disponível em: <http:// www.planalto.gov.br/ccivil_03/leis/19.394.htm>. Acesso em: 04/04/2012.

. Lei $n^{\circ}$ 9475, de 22 de Julho de 1997. Nova Redação ao artigo 33 da LDB. Brasília, DF: MEC, 1997; Disponível em: <http://portal.mec.gov.br/arquivos/pdf/ 19475.pdf>. Acesso em: 04/04/2013.

. Resolução CNE/CEB n 2/98. Diário Oficial da União, Brasília, 15 de abril de 1998, seção 1, p. 31. Disponível em: <http://portal.mec.gov.br/cne/arquivos/pdf/ rceb02_98.pdf>. Acesso em: 13/04/2013.

. Decreto $n^{\circ} 5626 / 2005$. Regulamenta a Lei no 10.436 , de 24 de abril de 2002, que dispõe sobre a Língua Brasileira de Sinais - Libras, e o art. 18 da Lei no 10.098, de 19 de dezembro de 2000. Diário Oficial da União, Presidência da República, Brasília, DF, 22 dez. 2005. Disponível em: <http:/www.planalto.gov. br/ccivil_03/_ato2004-2006/2005/decreto/d5626.htm>. Acesso em: 15/06/2013.

. Conselho Nacional de Educação. Conselho Pleno. Resolução $C N E / C P n^{\circ}$ 1/2006. Diretrizes Curriculares Nacionais para o Curso de Graduação em Pedagogia, licenciatura. Diário Oficial da União, Brasília, 16 de maio de 2006. Disponível em: $<$ http://portal.mec.gov.br/cne/arquivos/pdf/rcp01_06.pdf>. Acesso em: 18/04/2013.

COSTELLA, D. O fundamento epistemológico do ensino religioso. In: JUNQUEIRA, S.; WAGNER, R. (Orgs.). O Ensino Religioso no Brasil. Curitiba: Champagnat, 2004. p. 101-118.

DERISSO, J. L. Ensino religioso e ensino de história na rede oficial de ensino do estado de São Paulo. In: CONFERÊNCIAANUAL DAASSOCIAÇÃO INTERNACIONAL PARA O REALISMO CRÍTICO, 12., 2009, Niterói. Anais... Realismo e Emancipação Humana. Niterói, 2009, s/p. Disponível em: <http:/www.uff.br/iacr/ ArtigosPDF/65T.pdf>. Acesso em: 02/04/2013.

DUARTE, N. A anatomia do homem e a chave da anatomia do macaco: a dialética em Vygotsky e em Marx e a questão do saber objetivo na educação escolar. Educação e Sociedade, ano XXI, n. 71, p. 79-115, jul. 2000.

FONSECA, L. C. de S. "Você quer o fato científico ou o que eu realmente acredito?" O conflito entre religião e ciência nas escolas públicas municipais do Rio de Janeiro. In: REUNIÃO ANUAL DA ASSOCIAÇÃO DE PÓS-GRADUAÇÃO E PESQUISA EM EDUCAÇÃO, 29., 2006, p. 1-17, Caxambu. Anais... Disponível em: <http://www.anped.org.br/reunioes/29ra/trabalhos/trabalho/GT06-2305--Int. pdf $>$. Acesso em: 20/04/2013. 
FÓRUM NACIONAL PERMANENTE DO ENSINO RELIGIOSO (FONAPER). Parâmetros Curriculares Nacionais: Ensino Religioso (PCNER). 2. ed. São Paulo: AM Edições, 1997.

FREIRE, P. Pedagogia da esperança: um reencontro com a pedagogia do oprimido. São Paulo: Paz e Terra, 1996.

GARUTTI, S. O Ensino Religioso no contexto escolar. Revista Cesumar-Ciências Humanas e Sociais Aplicadas, v. 11, n. 2, p. 131-143, jul./dez. 2006. Disponível em: <http://www.cesumar.br/pesquisa/periodicos/index.php/revcesumar/article/ view/300>. Acesso em: 13/04/2013.

GATTI, B. A.; BARRETO, E. S. de S. (Coord.). Professores do Brasil: impasses e desafios. Brasília: UNESCO, 2009.

GIROUX, H. A.; SIMON, R. Cultura popular e pedagogia crítica: a vida cotidiana como base para o conhecimento curricular. In: MOREIRA, A. F.; SILVA, T. T. da (Orgs.). Currículo, cultura e sociedade. Trad. Maria A. Baptista. 2. ed. São Paulo: Cortez, 1995. p. 93-124.

; McLAREN, P. Formação do professor como uma contraesfera pública: a pedagogia radical como uma forma de política cultural. In: MOREIRA, A. F.; SILVA, T. T. da (Orgs.). Currículo, cultura e sociedade. Trad. Maria A. Baptista. 2. ed. São Paulo: Cortez, 1995. p. 125-154.

GRESSLER, L. A. Introdução à pesquisa: projetos e relatórios. 2. ed. rev. e atual. São Paulo: Loyola, 2004.

JUNQUEIRA, S. R. A. O Ensino Religioso no Brasil: estudo do seu processo de escolarização. Revista da Educação: Educere, Toledo, PR, v. 1, n. 2, p. 3-18, jul./ dez. 2001.

. A concepção de uma proposta: o Ensino Religioso em uma perspectiva pedagógica a partir do artigo 33 da LDB. Relegens Thréskeia Estudos e Pesquisa em Religião, v. 1, n. 1, p. 1-27, 2012. Disponível em: <http://ojs.c3sl.ufpr.br/ojs2/ index.php/relegens/article/viewFile/31047/19966>. Acesso em: 17/03/2013.

LIBÂNEO, J. C. Diretrizes Curriculares da Pedagogia: imprecisões teóricas e concepção estreita da formação profissional de educadores. Educ. Soc., Campinas, v. 27, n. 96 - Especial, p. 843-876, out. 2006. Disponível em: <http://www.cedes. unicamp.br>. Acesso em: 16/05/2013.

LOPES, A. C. Organização do conhecimento escolar: analisando a disciplinaridade e a integração. In: CANDAU, V. M. (Org.). Linguagens, espaços e tempos no ensinar e aprender. Rio de Janeiro: DP\&A, 2000. p. 147-163. 
MALACARNE, V. Caminhos e descaminhos na formação e na atuação dos professores de ciências. Cascavel, PR: Coluna do Saber, 2011.

MALVEZZI, M. C. F.; TOLEDO, C. de A. A. de. A formação do professor de Ensino Religioso no Paraná. Educere et Educare: Revista de Educação, v. 5, n. 9, p. 187-198, jan./jun. 2010.

MATURANA, H. A ontologia da realidade. Belo Horizonte: Editora UFMG, 1997.

OLIVEIRA, A. S. de. Formação às avessas: problematizando a simetria invertida na Educação de professores em serviço. In: REUNIÃO ANUAL DA ASSOCIAÇÃO NACIONAL DE PÓS-GRADUAÇÃO E PESQUISA EM EDUCAÇÃO, 32., 2009. GT14, v. único, 2009, p. 1-16. Disponível em: <http://www.anped.org. br/reunioes/32ra/arquivos/trabalhos/GT14-5855--Int.pdf> . Acesso em: 25/03/2013.

OLIVEIRA, L. B. Formação de docentes para o Ensino Religioso: perspectivas e impulsos a partir da ética social de Martinho Lutero. 2003. Tese (Doutorado) - EST: IEPG, São Leopoldo, 2003.

et al. Ensino Religioso: fundamentos e métodos. São Paulo: Cortez, 2007. (Coleção Docência em Formação. Série Ensino Fundamental).

PARANÁ. Conselho Estadual de Educação. Câmara de Legislação e Normas. Deliberação $n^{\circ}$ 03/02-CEE. Ensino Religioso nas redes públicas do Estado do Paraná. Curitiba, 9 de agosto de 2002. Disponível em: <http://celepar7cta.pr.gov.br/seed/ deliberacoes.nsf/7b2a997ca37239c3032569ed005fb978/d37cca3ae7ac904f03256 c3800674987/\$FILE/_p8himoqb2clp631u6dsg30cpd68o30cg_.pdf>. Acesso em: 02/03/2013.

. Deliberação n 07/02-CEE. Definição dos conteúdos do Ensino Religioso na escola pública. Curitiba, 6 de novembro de 2002. Disponível em: $<$ http://celepar7cta. pr.gov.br/seed/deliberacoes.nsf/7b2a997ca37239c3032569ed005fb978/456243610 6ce533003256c7c0064c71d/\$FILE/_o8himoqb2clp631u6dsg30dpd68o30cg_.pdf >. Acesso em: 02/03/2013.

Departamento de Ensino Fundamental. DEF/SEED. Instrução $n^{\circ}$ 001/02. Orienta a implantação do Ensino Religioso nas escolas de Ensino Fundamental da Rede Pública Estadual de educação básica. Curitiba: 12 de novembro de 2002. Disponível em: <www.gper.com.br/biblioteca_download.php?arquivold=172>. Acesso em: 10/04/2013.

. Parecer $n^{\circ}$ 464/03-CEE. Consulta acerca da Deliberação n. ${ }^{\circ}$ 3/02 - Ensino Religioso na escola pública. Curitiba, 2003. Disponível em: $<$ http://celepar7cta. pr.gov.br/seed/ pareceres.nsf/fef9bc43c12d0fe8032566c1006ce9e5/13fcffc2f20f 293703256d8e004c7aa5/\$FILE/ PA\%20464-03\%20Pr\%20254-03.doc>. Acesso em: 15/10/2013. 
Instrução Conjunta $n^{\circ} 005 / 04$. Orienta a implantação do Ensino Religioso nas escolas de Ensino Fundamental da Rede Pública Estadual de Educação Básica. Curitiba, 2004. Disponível em: <http://www.gper.com.br/index.php?sec=biber\&s ecaoId=6\&categoriaId=22>. Acesso em: 15/10/2013.

. Deliberação $n^{\circ} 01 / 06-C E E$. Curitiba, 2006. Disponível em: <http://www. pdfdownload.org/pdf2html/view_online.php?url=http\%3A\%2F\%2Fwww.cee. pr.gov.br\%2Farquivos\%2FFile\%2Fpdf\%2FDeliberacoes\%2F2006\%2Fdeliberac ao_01_06.pdf $>$. Acesso em: 07/03/2013.

. Secretaria de Estado da Educação do Paraná. Diretrizes Curriculares da $\overline{E d u c a c ̧ a ̃ o ~ B a ́ s i c a ~ E n s i n o ~ R e l i g i o s o . ~ C u r i t i b a, ~ 2008 . ~ D i s p o n i ́ v e l ~ e m: ~<h t t p: / / w w w . ~}$ educadores.diaadia.pr.gov.br/arquivos/File/diretrizes/dce_er.pdf $>$. Acesso em: 22/04/2013.

TOLEDO, C. de A. A. de; AMARAL, T. C. I. do; Análise dos Parâmetros Curriculares Nacionais para o Ensino Religioso nas escolas públicas. Revista HISTEDBR on-line, Campinas: Faculdade de Educação da UNICAMP, v. 1, n. 14, p. 1-17, jun./2004. Disponível em: $<$ http://www.periodicos.udesc.br/index.php/linhas/article/ viewFile/1248/1060>. Acesso em: 06/05/2013.

Recebido em 21 de outubro de 2013.

Aprovado em 25 de abril de 2014. 